CONCISE REPORT

\title{
Steroids, non-steroidal anti-inflammatory drugs, and sigmoid diverticular abscess perforation in rheumatic conditions
}

\author{
S Mpofu, C M A Mpofu, D Hutchinson, A E Maier, S R Dodd, R J Moots
}

Ann Rheum Dis 2004;63:588-590. doi: 10.1136/ard.2003.010355

Background: Corticosteroids and non-steroidal anti-inflammatory drugs are widely used for the treatment of rheumatic conditions, but their gastrointestinal damage significantly limits their use. Sigmoid diverticular abscess perforation (SDAP) is a very serious complication of diverticular disease. Objective: To determine the aetiology of large bowel SDAP in rheumatic conditions.

Methods: 64 patients with SPAD and 320 controls from a similar geographical area and of similar socioeconomic status were studied.

Results: The results showed that independently of rheumatic diagnosis corticosteroid treatment is strongly associated with SDAP (OR 31.9 (95\% Cl 6.4 to 159.2; $\mathrm{p}<0.001$ ), and nonsteroidal anti-inflammatory drugs only weakly associated (OR $1.8(95 \% \mathrm{Cl} 0.96$ to 3.4$) ; p=0.069)$. A rheumatic diagnosis is also strongly associated with the development of SDAP (OR 3.5 (95\% Cl 1.9 to 6.7); $p<0.001$ ).

Conclusions: SDAP has serious implications for patients and consumes many healthcare resources. Patients and physicians should be warned of this potential complication.

C orticosteroids and non-steroidal anti-inflammatory drugs (NSAIDs) have a wide range of side effects in the gastrointestinal tract. Within routine rheumatology practice both treatments are frequently prescribed. Recently, we reported two cases of sigmoid diverticular abscess perforation (SDAP) after corticosteroid treatment in patients with rheumatoid arthritis (RA). ${ }^{1}$

We have found 13 published reports of rheumatological patients with SDAP and all of these patients had received corticosteroids before the development of this complication. ${ }^{1-5}$

Myllykangas-Luosujarvi found a sixfold excess mortality in patients with RA as a result of diverticular disease. ${ }^{6}$ The author suggested that this increased mortality might be due to a particular drug prescribed in RA.

Corticosteroids are associated with abscess development. ${ }^{78}$ In perforated diverticular disease, several small case series have implicated NSAIDs and corticosteroids as possible aetiological factors. ${ }^{9}$ Accordingly we suggested that corticosteroids and NSAIDs might be associated with the development of SDAP and that this association would be important both for people with, or those without, a rheumatic disease. To test this hypothesis we undertook a case-control study to determine the importance of corticosteroid and NSAID treatment in the development of SDAP.

\section{PATIENTS AND METHODS}

We identified all patients at the University Hospital Aintree (a busy urban teaching hospital) who at discharge or death between 1995 and 2000 had records coded under the International classification of Disease (ICD) for a diagnosis of SDAP. A detailed case note examination was undertaken to determine if corticosteroids (oral or intravenous) or NSAID treatment (including aspirin) were being prescribed at the time of the SDAP and to determine any associated comorbidity. A diagnosis of SDAP was accepted only if there was operative or histological or necropsy evidence of perforation, to minimise variability in operative findings and to reduce bias from retrospective analysis.

The study sample comprised 64 patients (cases) with SDAP (38 female, 59\%), median age 70 years (range 39-91). Controls $(n=320)$ were identified from the computerised records of local general practitioners. Five controls were matched for age and sex with each case of SDAP. The case notes were studied to determine the drug treatment and comorbidity at the corresponding time of the SDAP in the matched case. The control group were from a similar geographical location and of the same socioeconomic status as the case patients.

\section{Statistical analyses}

Odds ratios and their 95\% confidence intervals were obtained from univariate and multivariate logistic regression analyses. Statistical analysis was undertaken using Stata version 7.0. Differences were considered to be significant for $\mathrm{p}$ values $<0.05$.

\section{RESULTS}

Twenty (31\%) of the cases died after surgery. Table 1 lists the comorbidity of the case patients and controls.

Overall, $31(48 \%)$ cases had a rheumatic diagnosis compared with only $55(17 \%)$ of the controls (odds ratio (OR) 4.5 (95\% confidence interval (CI) 2.6 to 8.0 ); $<<0.001$ ).

Table 2 compares the incidence of SDAP in cases and controls according to their NSAID and corticosteroid treatment.

A significantly higher proportion of the cases than of the controls were taking corticosteroids ( 10 (16\%) v $2(0.6 \%)$; OR 29.4 (95\% CI 6.3 to 138.1$) ; \mathrm{p}<0.001)$ and NSAID treatment $(27(42 \%) v 82(26 \%)$; OR 2.1 (95\% CI 1.2 to 3.7); $\mathrm{p}=0.008)$.

Table 3 shows a comparison of rheumatic condition, NSAIDs, and corticosteroid treatment in cases and controls.

When the effects of rheumatic disease, corticosteroid treatment, and NSAIDs on development of SDAP were assessed simultaneously in a multivariate logistic regression model, the association of rheumatic disease and corticosteroid treatment with SDAP remained highly significant (OR 3.5 (95\% CI 1.9 to 6.7 ); $p<0.001$ and OR 31.9 (95\% CI 6.4 to $159.2) ; \mathrm{p}<0.001$, respectively) but the association of NSAIDs

Abbreviations: NSAIDs, non-steroidal anti-inflammatory drugs; RA, rheumatoid arthritis; SDAP, sigmoid diverticular abscess perforation 
Table 1 Comorbidity of the cases and controls

\begin{tabular}{lcc}
\hline Diagnosis & $\begin{array}{l}\text { Cases }(n=64) \\
\text { No }(\%)\end{array}$ & $\begin{array}{l}\text { Controls }(n=320) \\
\text { No }(\%)\end{array}$ \\
\hline Rheumatoid arthritis & $3(5)$ & $1(0.3)$ \\
Dermatomyositis & $1(2)$ & $0(0)$ \\
Gout & $3(5)$ & $4(1)$ \\
Polyarteritis nodosa & $1(2)$ & $0(0)$ \\
Polymyalgia rheumatica & $1(2)$ & $4(1)$ \\
Osteoarthritis & $22(34)$ & $46(14)$ \\
COPD & $21(33)$ & $64(20)$ \\
Hypertension & $9(14)$ & $80(25)$ \\
Diverticular disease & $3(5)$ & $32(10)$ \\
\hline &
\end{tabular}

with SDAP became only borderline significant (OR 1.8 (95\% CI 0.96 to 3.4$) ; p=0.069)$. Neither of the interaction terms between rheumatic diagnosis and the treatments were significant, which implies that the observed effect of the treatments on SDAP is consistent in both rheumatic and nonrheumatic patients.

\section{DISCUSSION}

This study has demonstrated that corticosteroid treatment has a strong association, and NSAIDs a weak association, with SDAP, and this association is observed in people both with or without a rheumatic disease However, rheumatic disease is also strongly associated with development of SDAP. Our findings may, however, explain the association of a greatly increased morbidity and mortality rate from diverticular disease in patients with RA who are prescribed both treatments. ${ }^{6}$ The data on patients taking both treatments were sparse, and could not be formally analysed. Among the cases, only one patient was taking both treatments and only three taking two NSAIDs in this study (data not shown). SDAP is a very serious complication of diverticular disease. Accordingly, we observed a very high mortality rate among the cases $(31 \%)$, which is comparable with the mortality found in a Swedish 12 year study of 392 patients. ${ }^{10}$

NSAIDs are known to damage surface epithelial cells and increase colonic permeability. They also inhibit prostaglandins, which are important for maintaining the integrity of mucosal blood flow and responsible for creating an effective colonic mucosal barrier by stimulating secretion of mucin and bicarbonate. ${ }^{11}$ Corticosteroids have powerful immunosuppressive actions as well as anti-inflammatory effects and it is likely that these drugs impair the ability to contain a perforation in its early stages. ${ }^{9}$ Corticosteroids are associated with abscess formation and, probably, in those patients with diverticulitis, this infective process is worsened by corticosteroid treatment with the development of an abscess that subsequently perforates and is further exacerbated by NSAIDs. Corticosteroids also delay the consecutive healing

Table 2 Comparison of SDAP, in cases and controls receiving NSAIDs and corticosteroid treatment. Univariate analysis $\mathrm{OR}(95 \% \mathrm{Cl})$ and p value are obtained from univariate logistic regression

\begin{tabular}{lcccc}
\hline & $\begin{array}{l}\text { Cases* } \\
(\mathbf{n}=64) \\
\text { No }(\%)\end{array}$ & $\begin{array}{l}\text { Controls* } \\
(\mathbf{n}=320) \\
\text { No }(\%)\end{array}$ & OR $(95 \%$ Cl) & p Value \\
\hline $\begin{array}{l}\text { Rheumatic } \\
\text { condition }\end{array}$ & $31(48)$ & $55(17)$ & $4.5(2.6$ to 8.0$)$ & $<0.001$ \\
$\begin{array}{l}\text { Corticosteroids } \\
\text { NSAIDs }\end{array}$ & $10(16)$ & $27(0.6)$ & $29.4(6.3$ to 138.1$)$ & $<0.001$ \\
& $27(42)$ & $82(26)$ & $2.1(1.2$ to 3.7) & 0.008 \\
\hline
\end{tabular}

Table 3 Comparison of rheumatic condition, NSAIDs, and corticosteroid treatment in cases and controls. Multivariate analysis OR $(95 \% \mathrm{Cl})$ and $p$ value are obtained from multivariate logistic regression, which includes all three predictor variables in the model

\begin{tabular}{lcr}
\hline & OR $(95 \% \mathrm{Cl})$ & p Value \\
\hline Rheumatic condition & $3.5(1.9$ to 6.7$)$ & $<0.001$ \\
Corticosteroids & $31.9(6.4$ to 159.2$)$ & $<0.001$ \\
NSAIDs & $1.8(0.96$ to 3.4$)$ & 0.069 \\
\hline
\end{tabular}

process. Opiates are known to prolong the exposure of the diverticular wall to pathogens and putative agents by slowing bowel transit time. ${ }^{12}$ None of our study cohort cases were receiving opiates.

A number of groups of patients have an increased risk of diverticular abscess perforation. These include renal patients, patients with a lung transplant, ${ }^{13}{ }^{14}$ and patients with malignant brain tumours, ${ }^{15}$ including rheumatic conditions such as dermatomyositis, polyarteritis nodosa, ${ }^{16}$ and amyloidosis. ${ }^{17}$ Diverticular disease is common, particularly with increasing age, a phenomenon observed in this study group and, consequently, the development of complicated diverticular disease such as diverticulitis and abscess formation is not uncommon.

In summary, we have demonstrated a very strong association between corticosteroid treatment, and a weaker one between NSAID treatment, and the development of SDAP; this association is independent of that observed between rheumatic disease and SDAP. It is important that it is recognised that both treatments are associated with diverticular abscess perforation. Both physicians and patients should be warned of this potential therapeutic complication. There is a great need for research in this disease complication in order to explore and establish its aetiopathogenesis.

\section{Authors' affiliations}

S Mpofu, D Hutchinson, R J Moots, Academic Rheumatology Unit, University Hospital Aintree, Lower Lane, Liverpool L9 7AL, UK

C M A Mpofu, Gastroenterology Research group, Department of Medicine, University of Liverpool, Liverpool L69 3GA, UK

A E Maier, Park Street Surgery, Merseyside, UK

S R Dodd, Centre for Medical Statistics and Health Evaluation, School of Health Sciences, University of Liverpool, Liverpool, UK

This study was presented as a poster at the 65th Annual Scientific Meeting of the American College of Rheumatology, 10-15 November 2001, San Francisco, USA.

Correspondence to: Dr S Mpofu; smpofu@liv.ac.uk

Accepted 4 June 2003

\section{REFERENCES}

1 Hutchinson D, Lynch M. Sigmoid diverticular abscess perforation in 2 patients with rheumatoid arthritis treated with high dose corticosteroids. A cautionary tale. J Rheumatol 2001;28:1935-6.

2 Bowman S, Paice E, Binder A. Death from unsuspected diverticular disease in patients taking corticosteroids for polymyalgia rheumatica or giant cell arteritis. Br J Rheumatol 1991;30:159-60.

3 Oehler U, Bulatko A, Jenss H, Helpap B. Lethal complications in a case of sigmoid diverticulitis. A case report. Gen Diagn Pathol 1997;142:231-4.

4 Candelas G, Jover JA, Fernandez B, Rodriguez-Olaverri JC, Calatayud J. Perforation of the sigmoid colon in a rheumatoid arthritis patient treated with methylprednisolone pulses. Scand J Rheumatol 1998;27:152-3.

5 Durieux S, Rozenberg S, Bourgeois P. Complications of colonic diverticular disease during rheumatoid polyarthritis: 7 cases. Rev Med Interne 1999;20:50-3.

6 Myllykangas-Luosujarvi R. Diverticulosis-a primary cause of life threatening complications in rheumatoid arthritis. Clin Exp Rheumatol 1995;13:79-82. 
7 Bromage PR. Spinal extradural abscess: pursuit of vigilance. $\mathrm{Br} J$ Anaesth 1993;70:471-3

8 Ganzina F. High-dose medroxyprogesterone acetate (MPA) treatment in advanced breast cancer. A review. Tumori 1979:31:563-85.

9 Morris CR, Harvey IM, Stebbings WS, Speakman CT, Kennedy HJ, Hart AR. Epidemiology of perforated colonic diverticular disease. Postgrad Med J 2002;78:654-8.

10 Haglund U, Hellberg R, Johnsen C, Hulten L. Complicated diverticular disease of the sigmoid colon. An analysis of short and long term outcome in 392 patients. Ann Chir Gynaecol 1979;68:41-6.

11 Davies NM. Toxicity of nonsteroidal anti-inflammatory drugs in the large intestine. Dis Colon Rectum 1995;38:1311-21.

12 Painter NS, Truelove SC. The intraluminal pressure patterns in diverticulosis of the colon. Part II: the effect of morphine. Gut 1964;5:207-13.
13 Lederman ED, Conti DJ, Lempert N, Singh TP, Lee EC. Complicated diverticulitis following renal transplantation. Dis Colon Rectum 1998;41:613-18.

14 Fenton JJ, Cicale MJ. Sigmoid diverticular perforation complicating lung transplantation. J Heart Lung Transplant 1997:16:681-5.

15 Weiner HL, Rezai AR, Cooper PR. Sigmoid diverticular perforation in neurosurgical patients receiving high-dose corticosteroids. Neurosurgery
1993;33:40-3.

16 Okada M, Konishi F, Sakuma K, Kanazawa K, Koiwai H, Kaizaki Y. Perforation of the sigmoid colon with ischemic change due to polyarteritis nodosa. J Gastroenterol 1999;34:400-4.

17 Patel SA, al-Haddadin D, Schopp J, Cantave I, Duarte B, Watkins JL. Gastrointestinal manifestations of amyloidosis: a case of diverticular perforation. Am J Gastroenterol 1993;88:578-82.

\section{Clinical Evidence - Call for contributors}

Clinical Evidence is a regularly updated evidence based journal available worldwide both as a paper version and on the internet. Clinical Evidence needs to recruit a number of new contributors. Contributors are health care professionals or epidemiologists with experience in evidence based medicine and the ability to write in a concise and structured way.

\section{Currently, we are interested in finding contributors with an interest in} the following clinical areas:

Altitude sickness; Autism; Basal cell carcinoma; Breast feeding; Carbon monoxide poisoning; Cervical cancer; Cystic fibrosis; Ectopic pregnancy; Grief/bereavement; Halitosis; Hodgkins disease; Infectious mononucleosis (glandular fever); Kidney stones; Malignant melanoma (metastatic); Mesothelioma; Myeloma; Ovarian cyst; Pancreatitis (acute); Pancreatitis (chronic); Polymyalgia rheumatica; Post-partum haemorrhage; Pulmonary embolism; Recurrent miscarriage; Repetitive strain injury; Scoliosis; Seasonal affective disorder; Squint; Systemic lupus erythematosus; Testicular cancer; Varicocele; Viral meningitis; Vitiligo However, we are always looking for others, so do not let this list discourage you.

Being a contributor involves:

- Appraising the results of literature searches (performed by our Information Specialists) to identify high quality evidence for inclusion in the journal.

- Writing to a highly structured template (about 2000-3000 words), using evidence from selected studies, within 6-8 weeks of receiving the literature search results.

- Working with Clinical Evidence Editors to ensure that the text meets rigorous epidemiological and style standards.

- Updating the text every eight months to incorporate new evidence.

- Expanding the topic to include new questions once every 12-18 months.

If you would like to become a contributor for Clinical Evidence or require more information about what this involves please send your contact details and a copy of your CV, clearly stating the clinical area you are interested in, to Claire Folkes (cfolkes@bmigroup.com).

\section{Call for peer reviewers}

Clinical Evidence also needs to recruit a number of new peer reviewers specifically with an interest in the clinical areas stated above, and also others related to general practice. Peer reviewers are health care professionals or epidemiologists with experience in evidence based medicine. As a peer reviewer you would be asked for your views on the clinical relevance, validity, and accessibility of specific topics within the journal, and their usefulness to the intended audience (international generalists and health care professionals, possibly with limited statistical knowledge). Topics are usually 2000-3000 words in length and we would ask you to review between 2-5 topics per year. The peer review process takes place throughout the year, and our turnaround time for each review is ideally 10-14 days.

If you are interested in becoming a peer reviewer for Clinical Evidence, please complete the peer review questionnaire at www.clinicalevidence.com or contact Claire Folkes(cfolkes@bmigroup.com). 